\title{
Empirical research on the impact of credit on economic growth in Vietnam
}

\author{
Hung Manh Pham ${ }^{a^{*}}$ and Phuong Minh Nguyen ${ }^{a}$
}

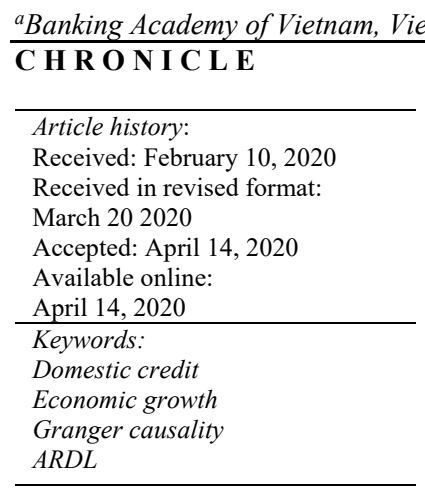

\section{A B S T R A C T}

This study examines the Granger causality between domestic credit and gross domestic product (GDP) as well as investigating this long-term relationship in Vietnam from 2004:Q1 to 2017:Q4 with the use of the autoregressive distributed lag (ARDL) model as the analysis method. Empirical results show that there was a two-way Granger causality relationship between credit and GDP. In addition, credit expansion had a negative impact on economic growth in Vietnam in the long term. Based on this research outcome, the study proposes a number of recommendations focusing on how to overcome the limitations of the bank credit supply channel.

(C) 2020 by the authors; licensee Growing Science, Canada

\section{Introduction}

Economic growth and the factors affecting economic growth are one of the top concerns of every country. Therefore, the impact of bank credit on economic growth is one of the topics that have received significant amount of attention from scholars around the world. Through various empirical studies in many countries, the researchers have very different perspectives on the impact of credit on economic growth. Many studies have shown that credit and economic growth have a positive relationship (Rajan \& Zingales, 1998; Levine et al., 2000), while others point out the inverse or non-linear relationship between these two variables (De Gregorio \& Guidotti, 1995; Beck et al., 2012; Arcand et al., 2015; Huang \& Lin, 2009). In recent years, the Vietnamese government has always considered that macroeconomic stability and economic growth are some of the most important goals of macroeconomic policy. Economic growth creates the basis for macroeconomic stability, employment, income, and social safety. Along with that, credit plays an important role in meeting the demand of firms' capital, ensuring the production process takes place regularly and continuously, and thus promoting the economic development. In recent years, more focus on the development of consumer credit and financial inclusion have boosted consumption, aggregate demand, and supported GDP growth. However, when the credit to GDP ratio is soaring, the economy will become more sensitive to the fluctuation of interest rates, thus increasing the risk of non-performing loans. In addition, the ratio of short-term deposit financing for medium-term and long-term loans of the whole banking system was approximately $28 \%$ by the end of 2018 , reduced significantly compared to the ratio of over $30 \%$ in 2016 . However, this ratio in numerous banks is still over $30 \%$, especially at some small joint-stock commercial banks, implying the maturity mismatch in the bank's balance sheet. Therefore, controlling domestic credit at a level that may both support economic growth and reduce systemic risk is the long-term goal of the Vietnamese government. In order to have an insight to the relation of domestic credit and economic growth in Vietnam 
and provide appropriate policy recommendations, this study will analyze the relationship between these two economic variables in the long run and the short run by using the ARDL model. To achieve the research objective, we use data in Vietnam from 2005 to 2017 on a quarterly basis with the variables of gross domestic product (GDP), credit and money supply.

The remainder of the article is structured as follows. Section 2 presents an overview of previous studies discussing the relationship between credit and economic growth. Section 3 explores the current situation of domestic credit and economic growth in Vietnam in recent years. Section 4 provides the information about the data and empirical methodology. In the fifth section, the study examines the Granger causality between credit and GDP as well as analyzes this long-term relationship in Vietnam using the ARDL model with data from Q1/2005 to Q4/2017. The final section of the report draws major conclusions and policy implications for Vietnam.

\section{Literature review}

The impact of credit on economic growth has received much attention from researchers around the world for a long time. To investigate the impact of lending activities, scholars often follow two main research directions: the first is to assess the impact of bank credit outstanding balance integrated into the model of the financial system impact, including bank credit and the stock market. Therefore, this research group often makes conclusions about the impact of both the banking system and the stock market. The second research direction focuses on analyzing the impact of bank credit on the economy. In particular, the variables for credit can be used are the total size of bank credit outstanding balance or analysis of each type of domestic credit.

The pioneer examining the effects of bank credit on economic development is Levine et al. (2000). GMM estimation (Generalized Method of Moments) was used with data sources from 63 countries between 1960 and 1995. The authors selected the ratio of the financial system debt to GDP, domestic credit to GDP, real GDP per capita, education level, government budget, exchange rate differences between formal and informal markets, trade openness index. The study confirms that the banking system has a positive impact on real GDP per capita and average labor productivity growth, thereby promoting economic development. Based on the research by Levine et al. (2000), Rioja and Valev (2004) divided 74 countries into three categories on the basis of their financial development level: low, medium and high in the period $1966-1995$. To evaluate the effect of credit on the economy, the authors also used the GMM estimation with the independent variables are private sector credit, the ratio of commercial banks assets to total assets of commercial banks and central banks, liquidity; the dependent variable is the real growth of GDP per capita. The results show that the impact of credit on economic growth is heterogeneous across countries. Specifically, the estimated coefficients for middle- and high-income countries are statistically significant, whereas they are not significant in low-income countries. In other words, the effect of credit on economic growth is positive and greater in countries with high financial development systems. Akpansung and Babalola (2011) used data from 1970 to 2008 in Nigeria with a Two-Stage least squares (2SLS) model to draw conclusions about the positive relationship between credit and economic growth. Timsina (2014) also presented evidence in Nepal from 1975 to 2013 that 1\% increase in private sector credit will contribute to real GDP growth of $0.4 \%$ in the long term. Accordingly, policymakers need to focus on long-term policies to effectively develop the banking system and financial markets in the direction of prioritizing credit towards the private sector in order to stimulate economic growth. Considering the relationship between credit and economic growth in different sectors based on data from 1993 - 2014 in Jordan, Ananzeh (2016) used a vector error correction model and Granger causality test. The study shows that bank credit outstanding balance in general and credit for sectors (such as agriculture, industry, construction, and tourism) in particular play a vital role and have long-term consequences on economic growth. Similar conclusions were verified in the study of Vazakidis and Adamopoulos (2009) and Belinga et al. (2016). Although there are many arguments supporting the opinion that the development of the financial system in general and domestic credit, in particular, has a constructive effect on economic growth, there are also many studies proving that the impacts of credit are not influential, or even negative. De Gregorio and Guidotti (1995) have found an inverse relationship between domestic credit and economic growth when using panel data in Latin American countries. The authors believe that the powerless legal environment causes credit adversely affect the economy. Similarly, Narayan (2013) confirms that the growth of bank credit may cast a shadow over economic upswing when using the GMM estimation for data from 65 countries between 1995 - 2011. Recently, Arcand et al. (2015) have demonstrated that when private sector credit reaches to a certain threshold (about 80 - 100\% of GDP), it might prevent economic growth. The relationship between credit growth and economic growth in Vietnam has been examined by both quantitative and qualitative methods, such as the study of Duong and Izumida (2002); Quach and Mullineux (2007), Anwar and Nguyen (2009). However, these studies do not yet provide an overall picture of credit and economic development in Vietnam. The studies of Duong and Izumida (2002) or Quach and Mullineux (2007) focused only on the role of credit for household economic growth; while Anwar and Nguyen (2009) just stopped at analyzing the role of credit for economic growth by province. Anwar and Nguyen (2009) applied panel data from 61 provinces and cities from 1997 to 2006 to investigate the relationship between financial development and economic growth. The research is built upon the GMM model and the observed variables in each province including the Gross Provincial Product (GPP), the credit-to-GPP ratio, the savings-to-GPP ratio, M2-to-GPP ratio, export value-to-GPP ratio, number of college students per 1,000 people by province, the added value from production activities by province, the value of FDI enterprises per capita, technology gap between FDI enterprises and domestic enterprises, inflation rate, public expenditure-to-GPP ratio by province and exchange rate. The authors found a positive correlation between credit ratio, savings and economic growth in Vietnam. Although the linkage of credit growth economic growth is no longer a new issue, there have not been many quantitative studies on this relationship in Vietnam so 
far, especially studies using quarterly data. Therefore, this study is expected to make more contribution on the theoretical basis and empirical evidence, thereby suggesting solutions for policymakers in Vietnam.

\section{The current situation of domestic credit and economic growth in Vietnam}

Vietnamese financial system is a bank-based system hence the commercial banks are the most important capital channels for the economy. The credit to GDP ratio in Vietnam is always superior compared to other countries in the region and the average level in East Asia. This led to the situation that economic growth largely depends on credit growth. In fact, data from 20132018 shows that Vietnam had a much greater credit growth rate than China and other Southeast Asian countries do. The Vietnam's high lending rate is partly maintained to serve the economic development target. The situation seemingly began to change in 2018. Thanks to favorable internal and external factors of 2018, Vietnam's economy recorded the most impressive growth speed in the past 10 years. After achieving a 6.8\% growth in 2017, the growth rate of GDP reached $7.08 \%$ in 2018 . At the same time, Vietnam witnessed the lowest credit expansion in 2018 for the past 5 years, recorded only $13.3 \%$. Since the impact of the global financial crisis in 2008 - 2009, the most recent period of low credit growth was in 2013 and 2014 . In the period of 2013 - 2014, the State Bank of Vietnam set the target of credit increase was only about 12-14\%. In 2018, credit growth also hit a low rate of $13.3 \%$. However, there were differences in terms of the relation between credit and GDP growth rate. In 2013 and 2014, slow credit growth caused GDP growth rate was also depressed (5.42\% and 5.98\% respectively). In 2018 , despite modest credit expansion, GDP increased considerably to $7.08 \%$, the greatest level in the past 10 years.

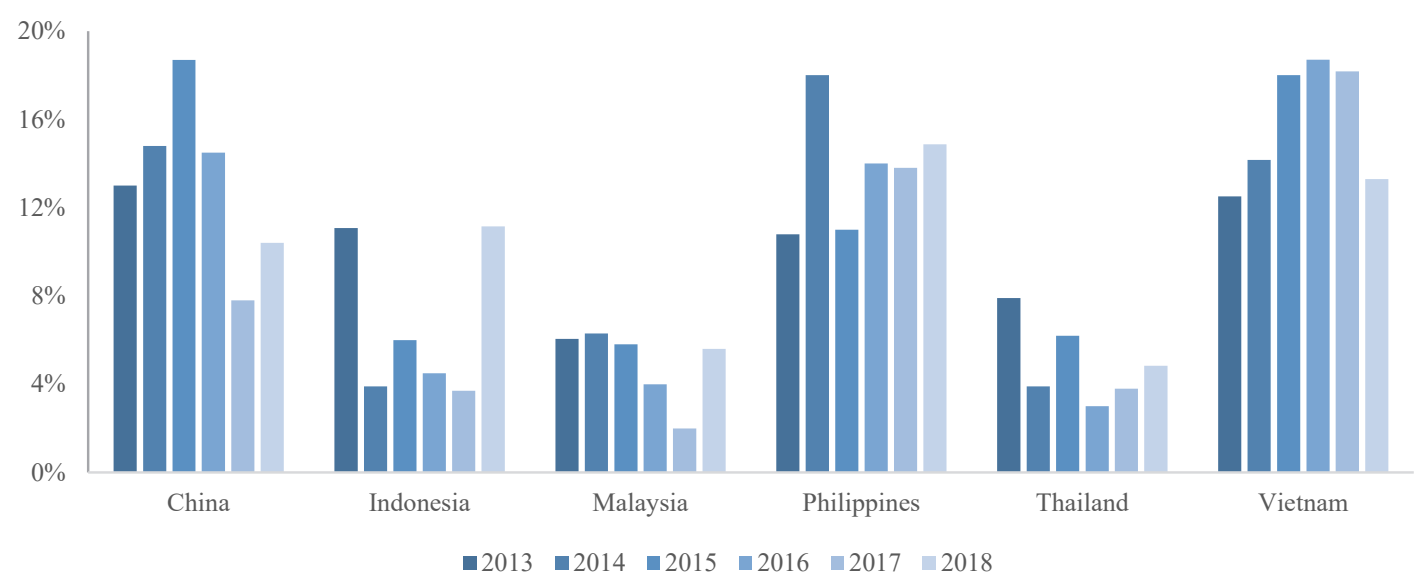

Fig. 1. Credit growth in some Asian countries

Source: World Bank

Statistics data from 2005 to 2017 might indicate that there is a positive correlation between credit growth and GDP growth, for example, $1 \%$ of GDP growth would demand 3\% of credit expansion. However, what happened in 2018 shows that this relationship was no longer affirmed when credit growth declined but GDP growth thrived. From the abovementioned facts, the authors use quantitative models to evaluate the relationship between credit growth and economic growth in the period of 2005-2017.

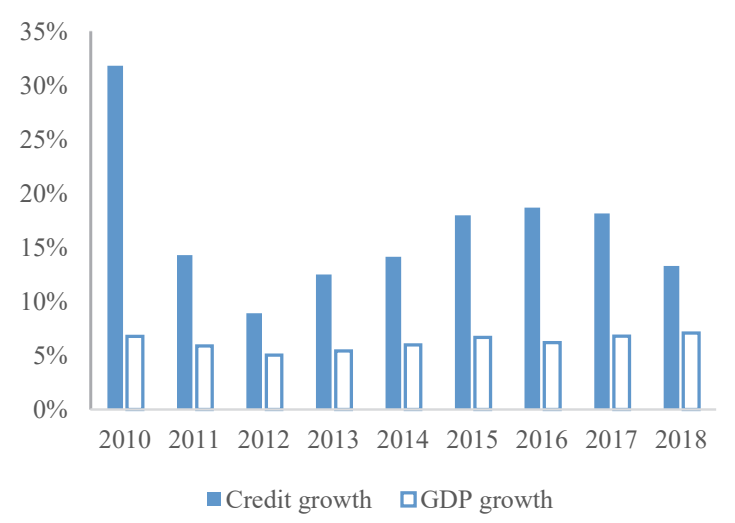

Fig. 2. GDP growth and Credit growth

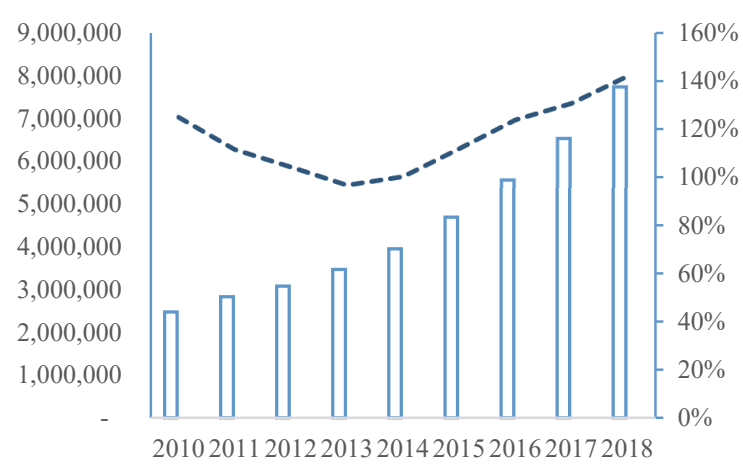

$\square$ Domestic Credit (bil VND) - -----Credit/GDP

Fig. 3. Credit growth and Credit/GDP 


\section{Methodology and data}

The main objective of this study is to examine the Granger causality between credit and GDP and assess the long-term effects of credit on GDP in Vietnam. The causal relationship between credit and GDP is tested within the VAR model based on three variables of GDP, credit and money supply according to the approach of Toda and Yamanato (1995). The VAR model is used assuming that all variables in the model are endogenous, so it is possible to test the two-way relationship between GDP and credit (DC). The money supply (M2) variable was added to the model because previous studies on the relationship between credit and GDP or studies on the transmission channel of monetary policy often used additional money supply variables. The model only uses three variables because the research time series is not too long and also to avoid reducing the degrees of freedom of the model. Moreover, the model results are firm and there is no autocorrelation between the residuals. The ARDL model is then used to assess the long-term impact of credit on GDP in Vietnam because the ARDL model is considered more appropriate than the VECM model when assessing the long-term relationship between the variables in a small sample. Our regression model is as follows:

$$
L G D P_{t}=\beta_{0}+\beta_{1} * L D C_{t}+\beta_{2} * L M 2_{t}+\varepsilon_{t}
$$

In addition to the credit variable (LDC) and gross domestic product (LGDP), the model also added the money supply variable (LM2) with a time series of data from Q1/2005 to Q4/2017. Time series lengths are selected based on data availability.

LGDP, LDC, and LM2 are natural logarithms of gross domestic product, real credit, and real money supply at 2010 comparative prices. Real GDP is converted from nominal GDP taken from the General Statistics Office using GDP deflator (baseline year 2010), collected from the World Development Indicators database of the World Bank. Real credit and real money supply are converted from nominal credit and money supply and the consumer price index (CPI, base year 2010) taken from the International Financial Statistics (IFS) of the IMF.

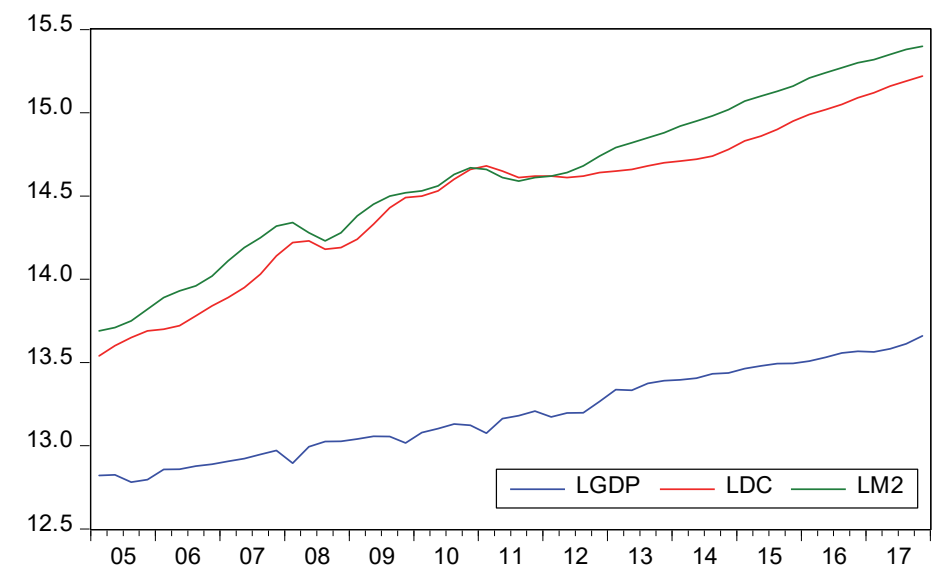

Fig. 4. GDP, money supply and credit in Vietnam, 2005-2017 (quarterly data)

Source: General Statistics Office, International Financial Statistics

The changing trend of the variables in the sample is outlined in Fig. 4. The descriptive statistics are presented in Table 1. The variables in the model are tested to stationarity using ADF (Augmented Dickey-Fuller) ) with the results showing that the series of data all stationary when taking first order differential (Table 2).

Table 1

Descriptive statistics of variables

\begin{tabular}{lccc}
\hline & & LDC & LM2 \\
\hline Mean & 13.19371 & 14.48462 & 14.62115 \\
Median & 13.16847 & 14.62000 & 14.62500 \\
Maximum & 13.65955 & 15.22000 & 15.40000 \\
Minimum & 12.78166 & 13.54000 & 13.69000 \\
Std. Dev. & 0.259244 & 0.461895 & 0.478214 \\
Skewness & 0.127452 & -0.477754 & -0.194334 \\
Kurtosis & 1.719412 & 2.266128 & 2.159329 \\
Jarque-Bera & 3.693911 & 3.145055 & 1.858549 \\
Probability & 0.157717 & 0.207520 & 0.394840 \\
Sum & 686.0730 & 753.2000 & 16000 \\
Sum Sq. Dev. & 3.427581 & 58069 & 52 \\
Observations & 52 & & 11.66313 \\
\hline
\end{tabular}


Table 2

Augmented Dickey-Fuller Test for stationarity

\begin{tabular}{cccc}
\hline Series & Prob. & Series & Prob. \\
\hline LGDP & 0.9740 & D(LGDP) & 0.0000 \\
LDC & 0.4235 & D(LDC) & 0.0000 \\
LM2 & 0.4574 & D(LM2) & 0.0000 \\
\hline
\end{tabular}

\section{Empirical results and discussion}

\subsection{Granger causality test}

Granger causality is tested according to the approach of Toda and Yamanato (1995) with the hypothesis H0: there is no causal relationship between variables. Therefore, the VAR model between LGDP, LDC, and LM2 variables is used to perform this test. Lag 5 is selected according to AIC standards. The model is robust and there is no autocorrelation between the residuals. The test results show that there is a 2-way Granger causality at the 5\% significance level between credit and GDP in Vietnam (Table 3).

Table 3

VAR Granger Causality/Block Exogeneity Wald Tests

\begin{tabular}{|c|c|c|c|}
\hline \multicolumn{4}{|l|}{ Dependent variable: LM2 } \\
\hline Excluded & Chi-sq & $\mathrm{df}$ & Prob. \\
\hline LDC & 5.412334 & 5 & 0.3677 \\
\hline LGDP & 12.32958 & 5 & 0.0305 \\
\hline All & 21.32132 & 10 & 0.0190 \\
\hline \multicolumn{4}{|l|}{ Dependent variable: LDC } \\
\hline Excluded & Chi-sq & df & Prob. \\
\hline LM2 & 24.88823 & 5 & 0.0001 \\
\hline LGDP & 13.11557 & 5 & 0.0223 \\
\hline All & 49.96096 & 10 & 0.0000 \\
\hline \multicolumn{4}{|l|}{ Dependent variable: LGDP } \\
\hline Excluded & Chi-sq & df & Prob. \\
\hline LM2 & 10.26786 & 5 & 0.0680 \\
\hline LDC & 11.61319 & 5 & 0.0405 \\
\hline All & 20.33853 & 10 & 0.0262 \\
\hline
\end{tabular}

\subsection{Bound testing for co-integration}

To test for co-integration among variables, we formulate the ARDL specification as follows:

$$
G D P_{t}=\beta_{0}+\beta_{1} * D C_{t}+\beta_{2} * M 2_{t}+\varepsilon_{t}
$$

where $\beta_{i}$ is a vector of long-run coefficients; $\varepsilon_{t}$ is the error term. Eq. (1) can be rewritten in error correction (ECM) form proposed by Pesaran et al. (2001) and Shin et al. (2014) as follows:

$$
\begin{aligned}
& \Delta G D P_{t}=\alpha_{0}+\alpha_{1} * G D P_{t-1}+\alpha_{2} * D C_{t-1}+\alpha_{3} * M 2_{t-1}+\sum_{i=1}^{q}\left(\rho_{1 i} * \Delta G D P_{t-i}\right)+\sum_{i=1}^{m}\left(\rho_{2 i} * \Delta D C_{t-i}\right)+ \\
& \sum_{i=1}^{n}\left(\rho_{3 i} * \Delta M 2_{t-i}\right)+\mu_{t}
\end{aligned}
$$

where $q, m, n$ indicate the lag length of variables. The short-term effects of domestic credit on GDP are reflected in: $\sum_{i=1}^{m} \rho_{2 i}$.

Based on the AIC statistics, the optimal lag lengths of GDP, DC and M2 are identified, accordingly, the following ARDL (1, $2,0)$ is used to explore credit's long-term effects. In addition, we use the Newey-West approach to work out standard errors of the estimated coefficients. As can be seen from Table 4, our model reveals no residual autocorrelation at the 5\% significance level.

Table 4

Correlogram Specification

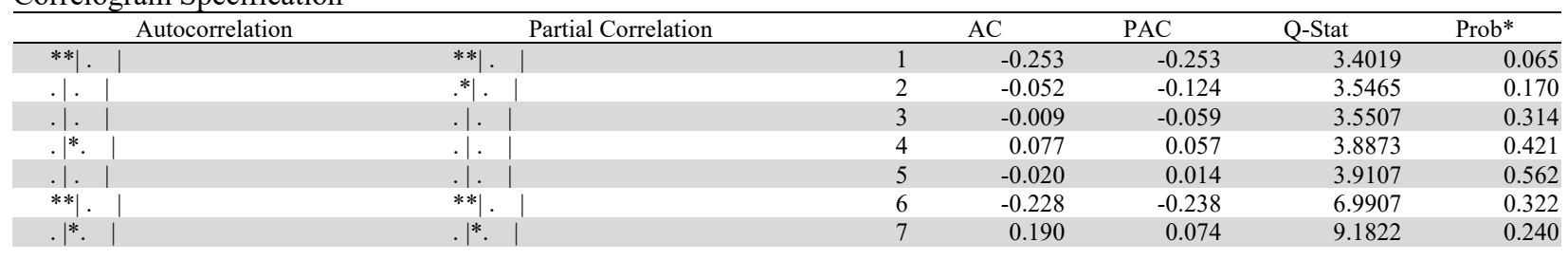


Table 4

Correlogram Specification (Continued)

\begin{tabular}{|c|c|c|c|c|c|c|}
\hline Autocorrelation & Partial Correlation & & $\mathrm{AC}$ & $\mathrm{PAC}$ & Q-Stat & Prob* \\
\hline **1. | & $* *||$. & 8 & -0.279 & -0.291 & 13.999 & 0.082 \\
\hline.$\left.\right|^{*}$ &.$\left.\right|^{*}$. & 9 & 0.196 & 0.096 & 16.438 & 0.058 \\
\hline.$* 1$. & .1 & 10 & -0.087 & -0.059 & 16.928 & 0.076 \\
\hline .1. & $*{ }^{*}$. & 11 & -0.044 & -0.100 & 17.056 & 0.106 \\
\hline.$\left.\right|^{*}$. &.$\left.\right|^{*}$. & 12 & 0.109 & 0.081 & 17.873 & 0.120 \\
\hline$* * \mid$. & $* * \mid$. & 13 & -0.208 & -0.241 & 20.914 & 0.075 \\
\hline$\left.\right|^{*}$ & .1 & 14 & 0.185 & 0.032 & 23.389 & 0.054 \\
\hline .1. & $\left.\right|^{*}$. & 15 & -0.007 & 0.136 & 23.393 & 0.076 \\
\hline .1. & ${ }^{*} \mid$. & 16 & 0.015 & -0.146 & 23.411 & 0.103 \\
\hline.$* 1$. & .1. & 17 & -0.115 & 0.016 & 24.444 & 0.108 \\
\hline.$\left.\right|^{*}$. & .1. & 18 & 0.142 & 0.069 & 26.071 & 0.098 \\
\hline.$\left.\right|^{*}$. & .1. & 19 & 0.096 & -0.009 & 26.838 & 0.108 \\
\hline.$* 1$. &.$\left.\right|^{*}$. & 20 & -0.117 & 0.151 & 28.029 & 0.109 \\
\hline.$\left.\right|^{*}$. & .1. & 21 & 0.080 & -0.061 & 28.601 & 0.124 \\
\hline$*$ & $*$ & 22 & -0.138 & -0.100 & 30.377 & 0.110 \\
\hline.$^{*}$. & $* \mid$. & 23 & -0.087 & -0.167 & 31.113 & 0.120 \\
\hline .1. & **1. & 24 & 0.037 & -0.082 & 31.248 & 0.147 \\
\hline
\end{tabular}

Bounds test results for co-integration suggest that there exists a long-term relationship between domestic credit, money supply and GDP at the $1 \%$ significance level (see Table 5).

Table 5

Bound test for co-integration

\begin{tabular}{lccrr}
\hline Test Statistic & Value & Signif. & $\mathrm{I}(0)$ & $\mathrm{I}(1)$ \\
\hline \hline & & & Asymptotic: $\mathrm{n}=1000$ & \\
F-statistic & 16.12928 & $10 \%$ & 4.19 & 5.06 \\
$\mathrm{k}$ & 2 & $5 \%$ & 4.87 & 5.85 \\
& & $2.5 \%$ & 5.79 & 6.59 \\
& 50 & $1 \%$ & 6.34 & 7.52 \\
Actual Sample Size & & & Finite Sample: $\mathrm{n}=50$ & 5.35 \\
& & $10 \%$ & 4.38 & 6.303 \\
& & $5 \%$ & 5.247 & 7.337 \\
\hline \hline
\end{tabular}

\subsection{ARDL estimation results and discussion}

The long-term relationship between GDP, domestic credit and M2 is illustrated by the following specification:

$$
L G D P=\quad \begin{array}{ll}
5.6628 \\
(0.225850)
\end{array} \quad+\quad \begin{aligned}
& 0.4671 * L D C \\
& (0.085994)
\end{aligned} \quad \begin{aligned}
& 0.9820 * L M 2 \\
& (0.081969)
\end{aligned}
$$

In which, the values in parentheses are standard errors of the estimated coefficients. The long-term coefficients of the variables are statistically significant at $1 \%$. Our results show that there is an inverse association between domestic credit and GDP. Specifically, a $1 \%$ increase in credit would cause GDP to fall $0.47 \%$ in the long term. Estimation results also reveal a longterm positive relationship between money supply and GDP (see Table 6).

Table 6

ARDL Long Run Form and Bounds Test

\begin{tabular}{lllll}
\hline Variable & Coefficient & Std. Error & t-Statistic & Prob. \\
\hline LDC & -0.467103 & 0.085994 & -5.431834 & 0.0000 \\
LM2 & 0.982023 & 0.081969 & 11.98042 & 0.0000 \\
C & 5.662781 & 0.225850 & 25.07321 & 0.0000 \\
\hline
\end{tabular}

$\mathrm{EC}=\mathrm{LGDP}-(-0.4671 \times \mathrm{LDC}+0.9820 \times \mathrm{LM} 2+5.6628)$

The error correction model results demonstrate that domestic credit has also a negative effect on GDP in the short term, besides, the short-term impact of credit appears greater than the long-term impact on GDP. Therefore, domestic credit has an adverse effect on GDP in the short- and long-term for the case of Vietnam. On the other hand, when credit deviates from equilibrium, GDP would react rather quickly to return to the equilibrium at a change rate of $54.7 \%$ in the first quarter. 
Table 7

ARDL estimation results in the form of error correction models

\begin{tabular}{lllll}
\hline Variable & Coefficient & Std. Error & t-Statistic & Prob. \\
\hline D(LDC) & -0.796888 & 0.162383 & -4.907448 & 0.0000 \\
D(LDC(-1)) & -0.332041 & 0.148614 & -2.234253 & 0.0306 \\
CointEq(-1)* & -0.547462 & 0.070940 & -7.717259 & 0.0000 \\
\hline
\end{tabular}

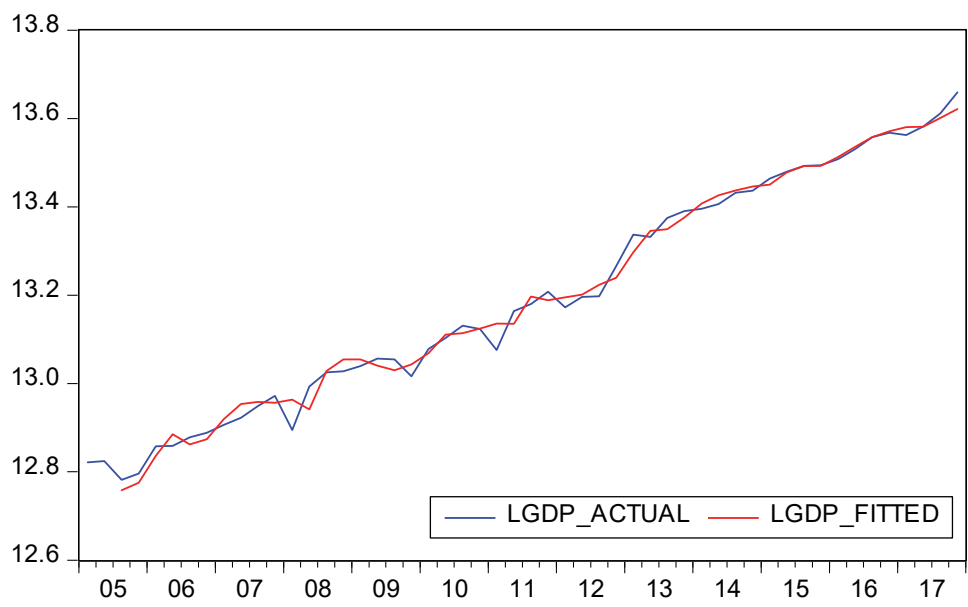

Fig 5. Comparison of actual GDP and estimation of ARDL model

The finding of an inverse relationship between credit and GDP in Vietnam is consistent with the research results of Arcand et al. (2015). It is shown that there is an inverse U-shaped relationship between the credit-to-GDP ratio and the GDP growth rate with the credit-to-GDP ratio threshold is from $80-100 \%$. In Vietnam, the ratio of credit to GDP in many periods exceeded $100 \%$ and is currently reaching about $120 \%$ in the fourth quarter of 2017 , so an increase in credit growth may impact negatively on economic growth.

\section{Conclusion and policy implications}

\subsection{Conclusion}

The results of the regression model indicate a long-term inverse relationship between domestic credit and economic growth. In other words, during periods of excessive credit growth, weak economic growth is witnessed and vice versa. A number of empirical studies (e.g., Ly et al., 2017) indicate that the periods of high credit growth are often associated with macroeconomic instability when inflation increases, bad debt rises uncontrollably, the ability to absorb capital of the economy is negatively affected. In these circumstances, credit growth plays a crucial role to maintain economic development, the banking system is forced to pump credit to keep the pace of growth, even though the efficiency of loan usage is not ensured. In recent years, credit expansion has started to cool down compared to the previous period, while economic growth has been more positive, which can be explained by the following points of view:

First of all, credit growth has been low but GDP growth has remained high in recent years, showing that credit quality has been improved. According to statistics of the State Bank of Vietnam, the credit structure in 2018 mainly focused on processing - manufacturing industries (increased 7.7\%), agriculture (increased 7.2\%), small and medium enterprises (increased over 3\%). Since 2017, credit for risky sectors such as securities investment and real estate is tightly controlled. By 2018, the SBV continued to issue Document 563/NHNN-TTGSNH, requesting credit institutions to increase their lending to the manufacturing sectors, restricting lending concentration for the real estate and construction sector. Commercial banks also need to ensure liquidity by complying with the regulation of the maximum ratio of short-term funds used for medium- and long-term loans. Secondly, the dependence of GDP growth on domestic credit is weakened due to the contribution of the FDI sector to the economy. In the first six months of 2018, the manufacturing sector was the fastest growing sector with a growth rate of nearly $13.02 \%$, the highest rate in the last seven years. The main contributor to the growth of the manufacturing industry is the production of electronics and components. While the FDI firms borrow small loans (or taking loans from foreign capital), they generate the growth of production and business without affecting the domestic credit. Thirdly, the impact of credit growth is often delayed. Some studies show that credit impacts on economic growth are lagged about 4 to 6 months. This implies that a slowdown in credit growth may signal a decline in economic growth after six months to a year later. However, this forecast needs to consider other factors. As analyzed above, the influences of credit on economic growth in the current period is no longer decisive. 


\subsection{Policy implications}

Based on the analysis of the relationship between credit growth and economic growth in the period 2005-2017, the authors proposed a number of policy recommendations to improve Vietnam's economic growth through enhancing the efficiency of bank credit. The State Bank of Vietnam needs to regularly request banks to report the credit quality analysis on the banking system. In necessary cases, the SBV will work directly with credit institutions to control risks. SBV also needs to require banks to strengthen internal inspection and strictly comply with the law on lending activities. Additionally, the SBV should direct the credit growth of the banking system close to the growth objectives of the whole economy and also announced the credit expansion target for each credit institution. In particular, according to Circular No. 41/2016/TT-NHNN, higher credit growth targets are prioritized for banks that implement requirements about capital adequacy ratio before the deadline. Commercial banks should enhance the credit supply to private enterprises, small and medium-sized enterprises, start-ups, that are oriented to become a key driver for future economic development. The biggest barrier for most businesses in the private sector is the lack of collateral eligible for credit access. While waiting for new regulations on lending without collaterals, the policymakers need to develop the "Credit Guarantee Fund" to create more favorable conditions for businesses to access credit capital.

\section{References}

Akpansung, A. O., \& Babalola, S. J. (2011). Banking sector credit and economic growth in Nigeria: An empirical investigation. $C B N$ Journal of Applied Statistics, 2(2), 51-62.

Ananzeh, I. E. N. (2016). Relationship between bank credit and economic growth: Evidence from Jordan. International Journal of Financial Research, 7(2), 53-63.

Anwar, S., \& Nguyen, L.P. (2009). Financial Development And Economic Growth In Vietnam. Springer Science and Business Media, LLC

Arcand, J. L., Berkes, E., \& Panizza, U. (2015). Too much finance?. Journal of Economic Growth, 20(2), 105-148.

Beck, T., Büyükkarabacak, B., Rioja, F. K., \& Valev, N. T. (2012). Who gets the credit? And does it matter? Household vs. firm lending across countries. The BE Journal of Macroeconomics, 12(1).

Beck, T., Degryse, H., \& Kneer, C. (2014). Is more finance better? Disentangling intermediation and size effects of financial systems. Journal of Financial Stability, 10, 50-64.

Belinga, T. \& Doumbe, E. (2016). Causality Relationship between Bank Credit and Economic Growth: Evidence from a Time Series Analysis on a Vector Error Correction Model in Cameroon. School of Economics, Wuhan University of Technology, China.

De Gregorio, J., \& Guidotti, P. E. (1995). Financial development and economic growth. World development, 23(3), 433-448.

Ductor, L., \& Grechyna, D. (2015). Financial development, real sector, and economic growth. International Review of Economics \& Finance, 37, 393-405.

Duong, P. B., \& Izumida, Y. (2002). Rural development finance in Vietnam: A microeconometric analysis of household surveys. World development, 30(2), 319-335.

Huang, H. C., \& Lin, S. C. (2009). Non-linear finance-growth nexus: A threshold with instrumental variable approach. Economics of Transition, 17(3), 439-466.

Levine, R., Loayza, N., \& Beck, T. (2000). Financial intermediation and growth: Causality and causes. Journal of monetary Economics, 46(1), 31-77.

Narayan, P. K., \& Narayan, S. (2013). The short-run relationship between the financial system and economic growth: New evidence from regional panels. International Review of Financial Analysis, 29, 70-78.

Pesaran, M. H., Shin, Y., \& Smith, R. J. (2001). Bounds testing approaches to the analysis of level relationships. Journal of Applied Econometrics, 16(3), 289-326.

Quach, H., \& Mullineux, A. (2007). The impact of access to credit on household welfare in rural Vietnam. Research In Accounting In Emerging Economies, 7, 279-307.

Rajan, R., \& Zingales, L. (1998). Financial development and growth. American Economic Review, 88(3), 559-586.

Rioja, F., \& Valev, N. (2004). Does one size fit all?: a reexamination of the finance and growth relationship. Journal of Development economics, 74(2), 429-447.

Shin, Y., Yu, B., \& Greenwood-Nimmo, M. (2014). Modelling asymmetric cointegration and dynamic multipliers in a nonlinear ARDL framework. In Festschrift in honor of Peter Schmidt (pp. 281-314). Springer, NY.

Thierry, B., Jun, Z., Eric, D. D., Yannick, G. Z. S., \& Landry, K. Y. S. (2016). Causality relationship between bank credit and economic growth: Evidence from a time series analysis on a vector error correction model in Cameroon. Procedia-Social and Behavioral Sciences, 235, 664-671.

Timsina, N. (2014). Impact of bank credit on economic growth in Nepal. Nepal Rastra Bank, Research Department, $22,1-23$.

Toda, H.Y., Yamamoto, T. (1995). Statistical inference in vector auto regressions with possibly integrated processes. Journal of Econometrics, 66, 225-250.

Vazakidis, A., \& Adamopoulos, A. (2009). Stock market development and economic growth. American Journal of Applied Sciences, 6(11), 34-40.

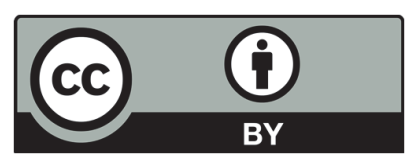

(C) 2020 by the authors; licensee Growing Science, Canada. This is an open access article distributed under the terms and conditions of the Creative Commons Attribution (CC-BY) license (http://creativecommons.org/licenses/by/4.0/). 